\title{
Red-light-emitting polymer composite based on PVDF membranes and Europium phosphor using Buriti Oil as plasticizer
}

\author{
Airton Germano Bispo-Jr ${ }^{\mathrm{a}, \mathrm{b}}$, Nagyla Alves Oliveira ${ }^{\mathrm{a}, \mathrm{b}}$, Celso Xavier Cardoso ${ }^{\mathrm{a}}$, \\ Sergio Antonio Marques Lima ${ }^{\mathrm{a}, \mathrm{b}}$, Aldo Eloizo Job ${ }^{\mathrm{a}}$, Igor Orlando Osorio-Román ${ }^{\mathrm{a}}$, \\ Caroline Silva Danna ${ }^{\mathrm{a}, \mathrm{c}}$, Ana Maria Pires ${ }^{\mathrm{a}, \mathrm{b}, *}$ \\ a São Paulo State University (Unesp), School of Technology and Sciences, Presidente Prudente, SP 19060-900, Brazil

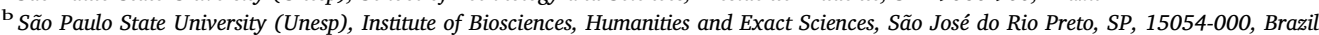 \\ ${ }^{\mathrm{c}}$ Universidad de Chile, Facultad de Ciencias, Departamento de Física, Las Palmeras, Santiago, 837.0415, Chile
}

\section{H I G H L I G H T S}

- $\mathrm{PVDF} / \mathrm{Ba}_{2} \mathrm{SiO}_{4}: \mathrm{Eu}^{3+} \quad$ luminescent membranes are candidates for LEDs application.

- A natural oil (Buriti oil) was successfully applied as a plasticizer in the PVDF matrix.

- $\mathrm{Ba}_{2} \mathrm{SiO}_{4}: \mathrm{Eu}^{3+}$ incorporation in PVDF matrix does not affect red phosphor luminescence.

- DSC scans confirmed the Buriti Oil plasticizer effect.

- Buriti oil and $\mathrm{Ba}_{2} \mathrm{SiO}_{4}$ :Eu addition increases the PVDF thermal stability.

\section{A R T I C L E I N F O}

\section{Keywords:}

$\mathrm{Ba}_{2} \mathrm{SiO}_{4}: \mathrm{Eu}^{3+}$

Natural plasticizer

Luminescent membrane

PVDF

Buriti oil
G R A P H I C A L A B S T R A C T

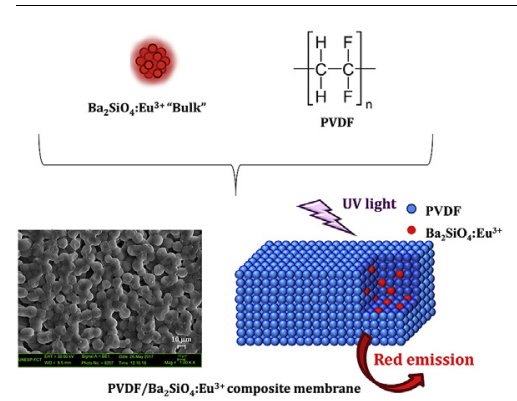

\begin{abstract}
A B S T R A C T
Rare-earth-doped phosphors immobilized in polymeric matrices find many applications like LEDs. However, little emphasis has been paid to the phosphor and plasticizer effect on the polymer structural, morphological and spectroscopic properties, for the development of functional devices. In this study, we are reporting for the first time the use of Buriti Oil (BO), a natural oil, as plasticizer in $\mathrm{Ba}_{2} \mathrm{SiO}_{4}: \mathrm{Eu}^{3+}$-doped PVDF composites membranes. Both, Buriti oil and phosphor amount were varied in the membrane synthesis. The drying temperature at $60^{\circ} \mathrm{C}$ leads to the formation of the $\alpha$-PVDF and the increase of the amount of BO up to $400 \mu \mathrm{L}$ decreases the PVDF crystallinity. Furthermore, the $\mathrm{BO}$ and phosphor additions increase the membrane thermal stability. Finally, the composite obtained with $10 \mathrm{wt} \%$ of $\mathrm{Ba}_{2} \mathrm{SiO}_{4}: \mathrm{Eu}^{3+}$ shows relative intense red emission with maximum at $612 \mathrm{~nm}$ originating from the $\mathrm{Eu}^{3+}$ radiative transitions in $\mathrm{Ba}_{2} \mathrm{SiO}_{4}$ lattice, making this composite material a good candidate for optical devices.
\end{abstract}

\section{Introduction}

Inorganic/Organic composites are appealing alternatives for a great diversity of systems especially for electro-optical applications [1]. In this context, rare-earth-doped phosphors immobilized into a polymeric matrix are receiving great attention due to high photoluminescence in combination with good physic-mechanical characteristic of the polymer [2]. This synergism between the phosphor and polymer properties is an

\footnotetext{
*Corresponding author. São Paulo State University (Unesp), School of Technology and Sciences, Department of Chemistry and Biochemistry, R. Roberto Simonsen, 305, 19060-900, Presidente Prudente, SP, Brazil.

E-mail address: ana.maria@unesp.br (A.M. Pires).
} 
interesting alternative for new composite materials synthesis which could be applied in several devices such as light emitting diodes (LEDs), gas sensors, chemosensors and full-color displays [3]. In addition, the use of additives as vegetal oils in composite polymeric membranes has become common to improve physical properties as flexibility, processing or softness [4]. Few studies exist on the use of vegetable oil in polymer technology, but these studies have been intensified in recent years [5]. Although great progress has been achieved, considering the importance of composite emitting materials, the demand for understanding the phosphor or the plasticizer influences on the polymer properties, and the need for new facile strategies to fabricate these systems are still highly desired [6,7].

Trivalent Europium ions, $\mathrm{Eu}^{3+}$, have been largely studied because of their long luminescence lifetime, high efficiency and narrow emission bands in the visible region, especially in the red [8]. All these characteristics infer to Europium based phosphors a wide range of applications as full-color displays, tunable lasers or light-emitting diodes [9]. $\mathrm{Eu}^{3+}$-doped materials can be effectively excited by UV and blue light yielding strong red emission assigned to the ${ }^{5} \mathrm{D}_{0} \rightarrow{ }^{7} \mathrm{~F}_{0-6}$ set of transitions, especially the hypersensitive transition, ${ }^{5} \mathrm{D}_{0} \rightarrow{ }^{7} \mathrm{~F}_{2}[10]$. The $\mathrm{Eu}^{3+}$ emission strongly depends on its site symmetry in the crystal structure [11]. In this sense, $\mathrm{Ba}_{2} \mathrm{SiO}_{4}: \mathrm{Eu}^{3+}$ is a red phosphor with intense emission under UV excitation; among its characteristics, we can highlight its high physical and chemical stabilities under intense irradiation power, and its transparency in the visible range [12]. $\mathrm{Ba}_{2} \mathrm{SiO}_{4}$ has orthorhombic structure and $P_{\text {nam }}$ space group [13]. Recently, we have published the successful sol-gel synthesis of a silica xerogel containing $\mathrm{Ba}^{2+}$ and $\mathrm{Eu}^{3+}$ ions [14] which can also act as precursor to obtain $\mathrm{Ba}_{2} \mathrm{SiO}_{4}: \mathrm{Eu}^{3+}$ red phosphors $[15,16]$. Besides the red strong emission, $\mathrm{Eu}^{3+}$ ions can easily be quenched by $\mathrm{CO}_{2}$ or $\mathrm{H}_{2} \mathrm{O}$ molecules, so the use of a protector as a polymeric matrix is a simple alternative to enhance the $\mathrm{Eu}^{3+}$ phosphor emission [17].

Usually, when a phosphor is applied in the LED emitter layer, the particles are immobilized in different kinds of glues as silicon, polyurethane or epoxy resin and this mix are used to cover a semiconductor chip that emits blue or UV light [18]. In these cases, it is difficult to control the thickness of the emitter layer and consequently the reproducibility of the emitted light. A way to overcome this problem is to immobilize the phosphor particles in a polymer matrix, as PVDF. The polyvinylidene fluoride (PVDF, $\mathrm{C}_{2} \mathrm{H}_{2} \mathrm{~F}_{2}$ ) is a semicrystalline polymer extensively studied because of its wide range of applications [19], being able to act as a polymer matrix due to its easy processing, excellent mechanical property, thermal stability and high chemical resistance [20] in comparison to other halogen-containing polymers like polytetrafluoroethylene (PTFE) [21]. This polymer is widely used as matrix for nano- or micron-sized particles [22,23] and its crystalline structure and molecular conformation are well described in the literature [24]. PVDF may crystallize in at least four distinct crystalline phases, known as $\alpha$ (form II), $\beta$ (form I), $\gamma$ (form III) and $\delta$ (form IV) [24]. Several effective methods to obtain PVDF membranes have emerged, including electrospinning [25], film-casting via polar solvents [26], rapid thermal treatment, and incorporation of nanoparticles [27].

In order to improve physical and chemical properties of polymeric matrices, usually chemical substances, such as Buriti oil, can be used as plasticizers [28]. The plasticizers should have lower molar mass than that of the polymer making it more homogeneous, flexible, softer, and easier to process [29]. The Buriti oil (obtained from Mauritiaflexuosa L.), BO, is an amazon vegetable oil with red-orange color and composed by fatty acids, tocopherols and carotenes [30]. The fatty acids present in the $\mathrm{BO}$ have long chains, longer than 10 carbon atoms in their structure. The BO application as plasticizer is reported in the literature for polymeric materials such as poly(methyl methacrylate) (PMMA) [31] and polystyrene (PS) or in starch films [32]. However, to the best of our knowledge, no study is reported yet about the use of BO as plasticizer for PVDF. Owing to the need to understand the phosphor and additive influence in polymeric matrices and the call to develop new efficient and stable materials for optical applications, the aim of the present paper is to report on the PVDF membranes fabrication containing $\mathrm{Ba}_{2} \mathrm{SiO}_{4}: \mathrm{Eu}^{3+}$ red phosphor by casting method using Buriti oil as plasticizer.

\section{Experimental}

\subsection{Synthesis of $\mathrm{Ba}_{2} \mathrm{SiO}_{4}: \mathrm{Eu}^{3+}(4 \%) / \mathrm{PVDF} / \mathrm{BO}$ composite membranes}

A sol-gel route to obtain pure $\mathrm{Ba}_{2} \mathrm{SiO}_{4}: \mathrm{Eu}^{3+}$ phosphor was recently developed in our research group [15]. The $\mathrm{Ba}_{2} \mathrm{SiO}_{4}: \mathrm{Eu}^{3+}(4 \%) / \mathrm{BO} /$ PVDF composite membranes were prepared applying the "casting" method by using PVDF (ATOCHEM), Buriti oil (Mundo dos oleos, $\left.\rho_{\left(23^{\circ} \mathrm{C}\right)}=0.92 \mathrm{~g} / \mathrm{cm}^{3}\right)$ and dimethylformamide (CINÉTICA, 99.8\%). A study of the BO amount influence in the structural, morphological and spectroscopic properties of the membrane was performed. For this, dimethylformamide $(10 \mathrm{~mL})$ was mixed with PVDF $(2 \mathrm{~g})$ and then a BO volume was added; this volume was varied as: $0,100,200,300,400$ and $500 \mu \mathrm{L}$. The mixture was heated at $80^{\circ} \mathrm{C}$ under stirring for two hours for the PVDF and oil dissolution, and after that, it was transferred to a Petri dish with a diameter of $9 \mathrm{~cm}$ and dried at $60^{\circ} \mathrm{C}$ for $6 \mathrm{~h}$. The PVDF membrane without BO was synthesized in order to compare with those containing the plasticizer.

The results described in the Results and Discussion section indicates that the best volume of $\mathrm{BO}$ is $400 \mu \mathrm{L}$. Therefore, this $\mathrm{BO}$ volume was fixed to produce the $\mathrm{Ba}_{2} \mathrm{SiO}_{4}$ : $\mathrm{Eu}^{3+}(4 \%) / \mathrm{BO} / \mathrm{PVDF}$ composite membranes. These composite membranes were synthesized in the same conditions as previously described varying the phosphor powder doping as: $2 \mathrm{wt} \%, 5 \mathrm{wt} \%, 10 \mathrm{wt} \%$ and $20 \mathrm{wt} \%$ in PVDF.

All PVDF membranes were characterized by: (i) scanning electron microscopy (SEM) using a Carls Zeiss model EVO LS15 scanning electron microscope with a detector of secondary electron (SE) in a high vacuum and at constant temperature; (ii) by thermogravimetric analysis (TGA) using a Netzsch equipment (model 204), approximate weight of $4 \mathrm{mg}$ of each sample in alumina crucible under purified nitrogen gas flux $(15 \mathrm{~mL} / \mathrm{min})$ and a heating rate of $10^{\circ} \mathrm{C} / \mathrm{min}$ from $25^{\circ} \mathrm{C}$ to $550{ }^{\circ} \mathrm{C}$ - TGA/FTIR was carried out with a coupling Bruker gas analysis cell; (iii) by differential scanning calorimetry (DSC) using a Netzsch equipment (model DSC 204), approximate weight of $2 \mathrm{mg}$ of each sample in alumina crucible, heating rate of $10^{\circ} \mathrm{C} / \mathrm{min}$ from $-90^{\circ} \mathrm{C}$ to $550^{\circ} \mathrm{C}$; (iv) by X-Ray Diffraction (XRD) using a Shimadzu model 600 diffractometer; and (v) by photoluminescence spectroscopy using a PerkinElmer model LS55 spectrometer (in the case of membranes with BO) equipped with continuous Xe lamp (9.9 W) excitation and using a Horiba Jobin Yvon Fluorolog-3 FL3-122 (in the case of $\mathrm{Ba}_{2} \mathrm{SiO}_{4}$ :Eu-doped membranes) equipped with an excitation and emission double monochromator, continuous Xe lamp (450 W) excitation. The slits were placed at 1.0 and $0.5 \mathrm{~nm}$ for excitation and emission, respectively. Emission lifetime was evaluated using a phosphorimeter Jobin Yvon, model FL-1040 equipped with Xe lamp $(25 \mathrm{~Hz})$.

\section{Results and discussion}

The membranes are white for lower amounts of $\mathrm{BO}$, and become yellowish as the contenting of $\mathrm{BO}$ increases, also the addition of the phosphor causes a darkness effect in the membrane color that become brownish. A photograph containing all the synthesized membranes is shown in Fig. S1, whereas it is possible to see that they are relatively homogeneous, except for the one doped with $20 \mathrm{wt} \%$ of $\mathrm{Ba}_{2} \mathrm{SiO}_{4}: \mathrm{Eu}^{3+}$, and for this reason, all other membranes had their thickness measured by a Mitutoyo micrometer, and the values are summarized in Table S1. By considering the set of membranes produced to evaluate the ideal volume of $\mathrm{BO}$, the thickness increases when $\mathrm{BO}$ is added to the mixture. Statistically, all membranes containing BO has the same thickness, being observed a slightly tendency of thickness increase as the amount of $\mathrm{BO}$ increases up to $400 \mu \mathrm{L}$ of $\mathrm{BO}$. Besides, when the $\mathrm{BO}$ amount is 

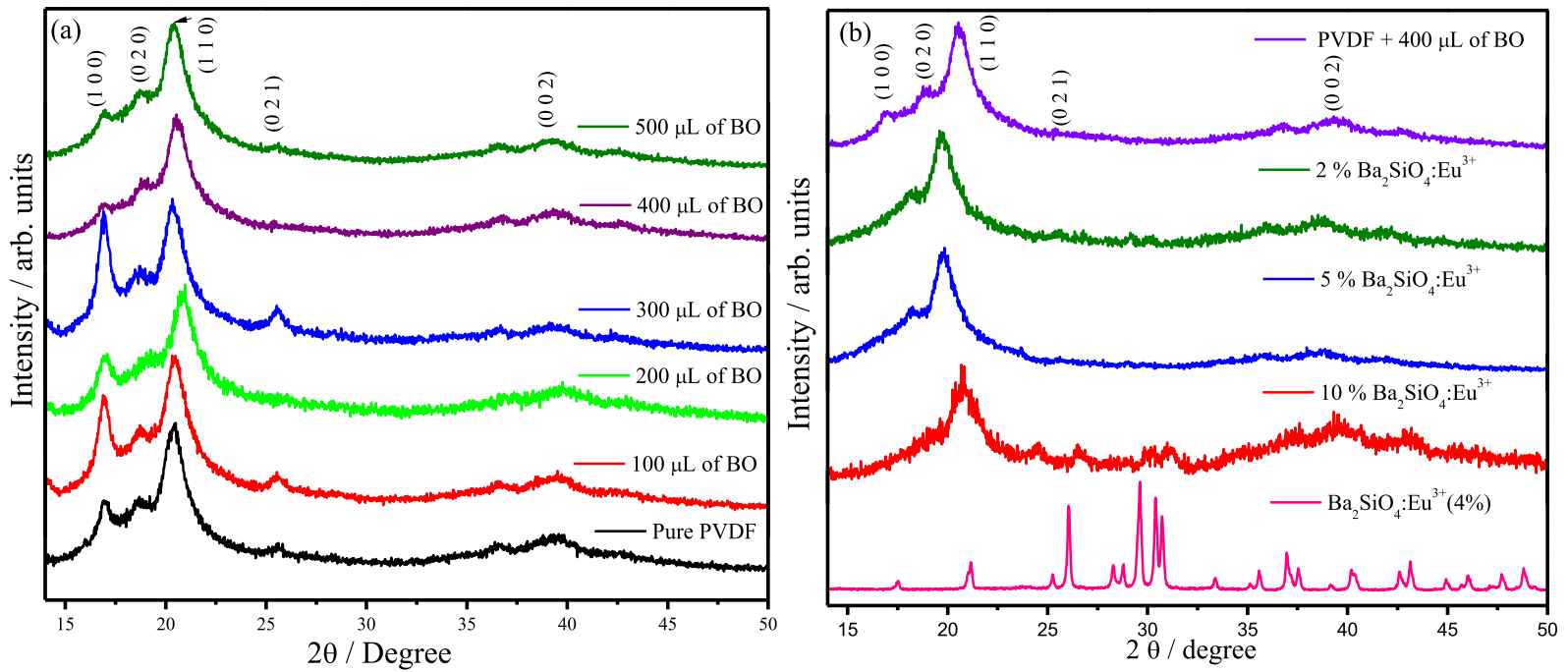

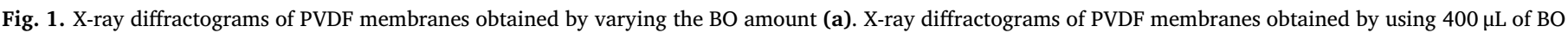
and varying the $\mathrm{Ba}_{2} \mathrm{SiO}_{4}: \mathrm{Eu}^{3+}$ phosphor concentration (b).

greater than $400 \mu \mathrm{L}$, the membrane exhibits an oily texture, indicating a $\mathrm{BO}$ saturation in the membrane. This observation indicates that the $400 \mu \mathrm{L}$ volume of $\mathrm{BO}$ is the most suitable for the production of the composite membranes. A tendency of thickness decreasing was observed with the addition of $\mathrm{Ba}_{2} \mathrm{SiO}_{4}: \mathrm{Eu}^{3+}$.

The X-ray diffraction profiles of the PVDF membranes with different amount of BO are shown in Fig. 1(a), and exhibit five peaks around $17^{\circ}$,

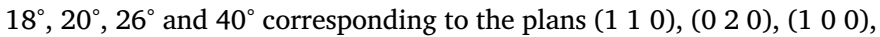
$\left(\begin{array}{lll}0 & 2 & 1\end{array}\right)$ and $\left(\begin{array}{lll}0 & 0 & 2\end{array}\right)$ respectively, characteristic of the $\alpha$-PVDF phase (JCPDS-38-1638) according to A. J. Lovinger [33]. All $2 \theta$ Bragg angle for the indexed $\alpha$-PVDF phase are also listed in Table S1. The large peaks FWHM values indicate the low crystallinity of the membranes and the PVDF semicrystalline nature. The crystallinity of the samples were calculated by calorimetry and will be presented and discussed later. In addition, X-ray data do not show others PVDF phases. In this sense, Wang et al. [34] observed a similar effect on the PVDF crystallinity when the membranes were formed at $60^{\circ} \mathrm{C}$. J. Hirschinger et al. reported that in the $\alpha$-PVDF phase (monoclinic, $P 2_{1} / c$; $a=4.96 \AA$, $\mathrm{b}=9.64 \AA, c=4.62 \AA, \beta=90^{\circ}$ ), the chains adopt a trans-cis-type conformational structure (TCTC), placing the $\mathrm{H}$ and $\mathrm{F}$ atoms alternately on each side of the chain. Thereby, this phase is thermodynamically more stable than the others PVDF phases, since it results in the longest possible distance between the fluorine atoms [35]. In this sense, the changes in membranes peak position indicate that the $\mathrm{BO}$ concentration influences the PVDF semicrystalline structure. These modifications can be related to variations in the PVDF chain size and organization, in the degree of crystallinity and changes in the strengths of the chains interaction that maintain them together. In addition, variations of the peaks relative intensities can be associated to modifications in the crystallite size of PVDF particles [36].

Fig. 1(b) shows the X-ray diffractogram of PVDF composite membranes obtained by using $400 \mu \mathrm{L}$ of $\mathrm{BO}$ and varying the $\mathrm{Ba}_{2} \mathrm{SiO}_{4}: \mathrm{Eu}^{3+}$ phosphor content. The X-ray pattern of the $\mathrm{Ba}_{2} \mathrm{SiO}_{4}: \mathrm{Eu}^{3+}$ phosphor corresponds to the monophasic orthorhombic $\mathrm{Ba}_{2} \mathrm{SiO}_{4}\left(P_{\text {nam }}\right)$ (JCPDS 70-2113) structure, and it is in accordance with the data published by us previously [15]. As the $\mathrm{Ba}_{2} \mathrm{SiO}_{4}: \mathrm{Eu}^{3+}$ content increases, the PVDF (1 0 0) plan disappears and the (lllll 110 ) peak position shifts to smaller Bragg angle values, indicating that PVDF crystallization is inhibited by the $\mathrm{Ba}_{2} \mathrm{SiO}_{4}: \mathrm{Eu}^{3+}$ particles. J. Song et al. obtained similar results for $\mathrm{La}_{2} \mathrm{O}_{3}$-doped $\alpha$-PVDF membranes [36].

SEM images of PVDF membranes with different content of BO are shown in Fig. S2, revealing agglomerated spherical microstructures connected by necks on the membrane surface, with diameter near to
$9.7 \mu \mathrm{m}$ that increases approximately up to $14 \mu \mathrm{m}$ when the concentration of the $\mathrm{BO}$ increases in the mixture. These microstructures are probably composed by spherulites according to the literature $[37,38]$. When $\mathrm{BO}$ was added into the PVDF membrane, some cavities were observed in the PVDF micro spherulites. Similar profile was also related by J. A. Dures et al. in poly(methyl methacrylate) membranes containing BO [31]. These cavities exhibit an oval shape and arise because during the preparation of the polymeric membranes with $\mathrm{BO}$, the solvent is evaporated and consequently, the oil coagulates into the polymer matrices. Then, phase separation is established after total solvent evaporation thus, resulting in materials showing distinct micro domains of BO inside the matrices. In another work, J. A. Duraes et al. showed that the oval-shaped cavities can be correlated to the intermolecular interactions between the polymer and the oil [39]. Although these interactions have low energy, they are present in a vast quantity leading to a good dispersion of BO in the matrix. SEM images of PVDF membranes obtained by adding $400 \mu \mathrm{L}$ of $\mathrm{BO}$ and varying the $\mathrm{Ba}_{2} \mathrm{SiO}_{4}: \mathrm{Eu}^{3+}$ concentration are shown in Fig. S3. $\mathrm{Ba}_{2} \mathrm{SiO}_{4}: \mathrm{Eu}^{3+}$ phosphor itself has irregular-shaped particles, characteristic of sol-gel method catalyzed by acid [40]. Membranes with low $\mathrm{Ba}_{2} \mathrm{SiO}_{4}: \mathrm{Eu}^{3+}$ concentration are formed by spheroidal-shaped particles connected by necks, resulting in a high agglomeration degree. On the other hand, the membrane with $10 \mathrm{wt} \%$ of $\mathrm{Ba}_{2} \mathrm{SiO}_{4}: \mathrm{Eu}^{3+}$ has a more regular distribution of particles with diameter of $9 \mu \mathrm{m}$, smaller than those observed in the PVDF membrane with $400 \mu \mathrm{L}$ of BO, Fig. 2.

The chemical mapping images for the PVDF membrane obtained by using $400 \mu \mathrm{L}$ of $\mathrm{BO}$ and $10 \mathrm{wt} \%$ of $\mathrm{Ba}_{2} \mathrm{SiO}_{4}: \mathrm{Eu}^{3+}$ are viewed in Fig. 3 . Just $\mathrm{C}, \mathrm{F}$ and $\mathrm{O}$ elements can be detected in the PVDF particle surface. Carbon comes from PVDF chains and BO, F comes from PVDF chains and $\mathrm{O}$ comes from fatty acids in $\mathrm{BO}$ and all the three atoms have homogeneous distribution in the PVDF. However, no signal related to $\mathrm{Ba}$, Eu or $\mathrm{Si}$ atoms are observed in the chemical mapping. This observation leads us to conclude that the phosphor particles are inside the membrane and not on the surface.

Thermogravimetric analysis and DTG curves for the PVDF membranes with BO are in Fig. S4. The PVDF membranes present a good thermal stability, up to at least $350{ }^{\circ} \mathrm{C}$. The high stability of the membranes could be correlated with the high electronegativity of the fluorine atoms composing the polymer chain and their high $\mathrm{C}-\mathrm{F}$ bond dissociation energy. Above $350{ }^{\circ} \mathrm{C}$, the PVDF begins to degrade releasing hydrogen fluoride, monomers and small amounts of $\mathrm{C}_{4} \mathrm{H}_{3} \mathrm{~F}_{3}$, as reported in literature [41,42] and confirmed by TG measurements coupled to FTIR/ATR (Fig. S5). Therefore, PVDF thermal degradation 


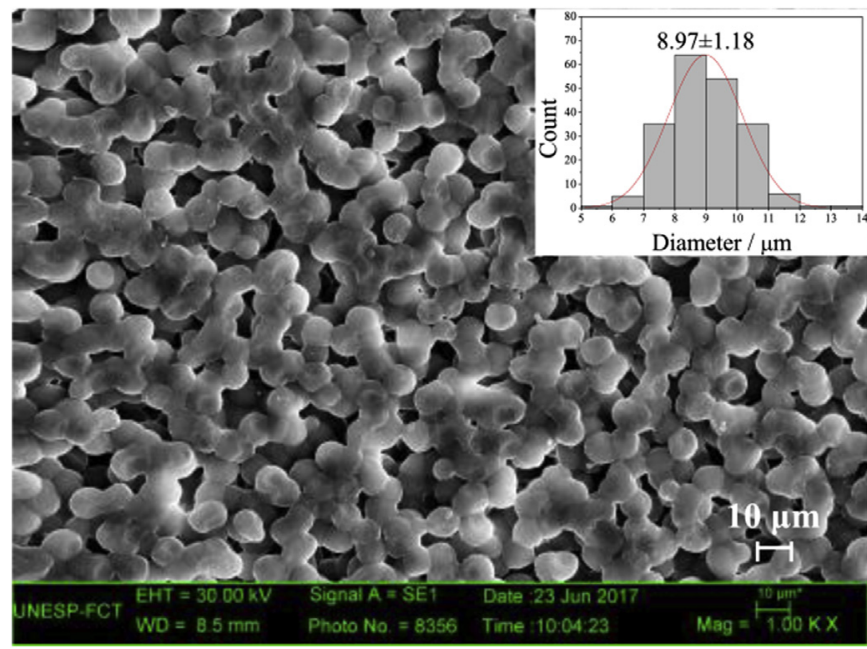

Fig. 2. Scanning electron microscopy images (SEM) with 1000 times magnification of the PVDF membranes obtained by using $400 \mu \mathrm{L}$ of BO with $10 \mathrm{wt} \%$ of $\mathrm{Ba}_{2} \mathrm{SiO}_{4}: \mathrm{Eu}^{3+}$.
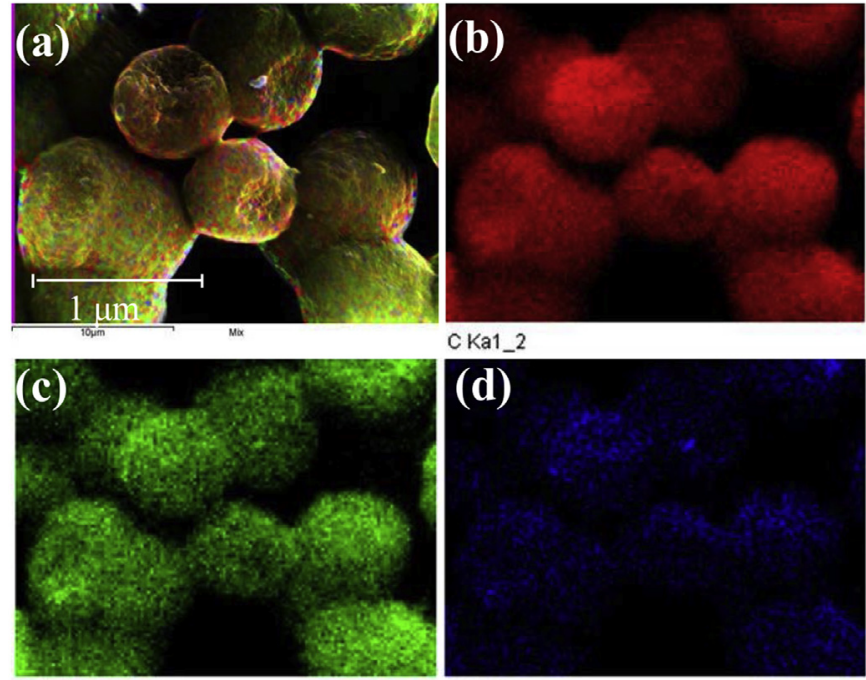

F Ka1_2

O Ka1

Fig. 3. Chemical mapping of the PVDF membrane synthesized by using $400 \mu \mathrm{L}$ of $\mathrm{BO}$ and doped with $10 \mathrm{wt} \%$ of $\mathrm{Ba}_{2} \mathrm{SiO}_{4}: \mathrm{Eu}^{3+}$. In (a), atoms of carbon, fluorine and oxygen are showed together, in (b) only carbon, in (c) only fluorine, and in (d) only oxygen atoms. mechanism is dominated by the hydrogen fluoride (HF) release, consequently leading to several chemical reactions including the formation of carbon-carbon double bonds or polymer cross-linking formation. The thermal decomposition of $\mathrm{BO}$ takes place in two steps, see Fig. S4. The first one near to $260^{\circ} \mathrm{C}$ is due to the release of volatile components and the second one around $425{ }^{\circ} \mathrm{C}$ indicates that the fatty acids break down completely [31]. Moreover, Fig. S4 shows that the more BO amount is added, an increase in the PVDF thermal stability is observed, which can be also verified in Table 1 . Besides, the loss weight between 405 and $501{ }^{\circ} \mathrm{C}$ (PVDF decomposition temperature range) decreases when $\mathrm{BO}$ is in the membrane up to $400 \mu \mathrm{L}$, for higher concentration the loss weight increases again. These observations confirm that $\mathrm{BO}$ is intensifying the interaction strength among PVDF chains and as a consequence, making it more difficult for the polymer to degrade. An explanation for this is the fact that fat acids constituting the $\mathrm{BO}$ provide a source of trapping radicals protecting the PVDF chain [43].

Fig. 4 shows the TGA and DTG thermograms that illustrate the thermal behavior of the PVDF/BO membranes with $\mathrm{Ba}_{2} \mathrm{SiO}_{4}: \mathrm{Eu}^{3+}$. $\mathrm{Ba}_{2} \mathrm{SiO}_{4}: \mathrm{Eu}^{3+}$ phosphor exhibits a loss weight of $10.51 \% \mathrm{w} / \mathrm{w}$ between $25^{\circ} \mathrm{C}$ and $600{ }^{\circ} \mathrm{C}$ with maximum at $300^{\circ} \mathrm{C}$ indicated by DTG. This mass loss can be attributed to the thermal decomposition of amorphous carbonate that forms on the phosphor surface [15]. When $\mathrm{Ba}_{2} \mathrm{SiO}_{4}: \mathrm{Eu}^{3+}$ phosphor is included in the membrane composition, a decrease of the loss weight is observed for the sample with $10 \mathrm{wt} \%$ of the phosphor, all others samples have similar losses (See Table 1).

The decomposition temperature slightly increases with the $\mathrm{Ba}_{2} \mathrm{SiO}_{4}: \mathrm{Eu}^{3+}$ concentration in the membrane (see Fig. 4(b) and Table 1), this observation indicates that the attraction forces among the $\mathrm{PVDF}, \mathrm{BO}$ and $\mathrm{Ba}_{2} \mathrm{SiO}_{4}: \mathrm{Eu}^{3+}$ improve the thermal stability of the composite. Similar results were also observed by F. S. Al-Hazmi et al. for $\mathrm{Cu}_{2} \mathrm{O}$ particles in PVDF membranes [44]. The improvement of the thermal stability due to the $\mathrm{Ba}_{2} \mathrm{SiO}_{4}: \mathrm{Eu}^{3+}$ particles incorporation in the PVDF may be related to the packing of the polar crystalline $\alpha$-phase by the ionic phosphor particles [45]. This occurs because silicate materials obtained from sol-gel synthesis usually show high polarity on particle surface due to the presence of Si-O groups [15]. In this way, this attraction between the PVDF chains and the phosphor particle surface can provide an increase in the thermal stability behavior of PVDF chains.

The DSC analysis gives further insight into the thermal behavior of the membranes as illustrated in Fig. S6. For pure BO, the DSC scan exhibits two endothermic events, the first around $-17^{\circ} \mathrm{C}$ $\left(\Delta H=43.9 \mathrm{~J} \mathrm{~g}^{-1}\right)$ associated to a solid phase transition of the oil $[46,47]$, and the second is a broad peak at $433.2^{\circ} \mathrm{C}$ related to the BO decomposition, as it was shown by the TG measurement. For the PVDF membranes are also observed two events: an exothermic peak at $480{ }^{\circ} \mathrm{C}$ attributed to the PVDF decomposition, and an endothermic peak around $170{ }^{\circ} \mathrm{C}$ attributed to the PVDF melting point $\left(T_{m}\right)$ characteristic of the PVDF $\alpha$-phase [48]. Addition of BO into the membranes leads a slight decrease in the PVDF melting point, Table 2. These differences in $T_{\mathrm{m}}$ are related to the differences in the crystalline organization

Table 1

Loss weight in different temperature ranges obtained from TG and maximum decomposition temperature for BO and PVDF obtained from DTA curves.

\begin{tabular}{|c|c|c|c|c|c|c|}
\hline \multirow[t]{2}{*}{ Membrane } & \multicolumn{3}{|c|}{ Loss weight/\% } & \multirow[t]{2}{*}{ BO Maximum decomposition $/{ }^{\circ} \mathrm{C}$} & \multicolumn{2}{|c|}{ PVDF Maximum decomposition $/{ }^{\circ} \mathrm{C}$} \\
\hline & $25-300{ }^{\circ} \mathrm{C}$ & $300-405^{\circ} \mathrm{C}$ & $405-501{ }^{\circ} \mathrm{C}$ & & & \\
\hline PVDF & -3.28 & -1.72 & -62.77 & - & - & 437.0 \\
\hline BO & -1.55 & -98.00 & - & 390.1 & - & - \\
\hline $\mathrm{PVDF}+100 \mu \mathrm{L}$ of $\mathrm{BO}$ & -2.49 & -4.93 & -61.05 & 375.1 & 425.3 & 451.1 \\
\hline $\mathrm{PVDF}+200 \mu \mathrm{L}$ of $\mathrm{BO}$ & -2.49 & -8.88 & -57.93 & 373.4 & 422.1 & 441.1 \\
\hline PVDF $+300 \mu \mathrm{L}$ of $\mathrm{BO}$ & -1.34 & -8.91 & -56.61 & 370.3 & 425.9 & 452.1 \\
\hline $\mathrm{PVDF}+400 \mu \mathrm{L}$ of $\mathrm{BO}$ & -2.26 & -14.07 & -53.29 & 383.4 & 426.9 & 442.4 \\
\hline $\mathrm{PVDF}+500 \mu \mathrm{L}$ of BO & -1.45 & -13.80 & -53.55 & 379.3 & 424.8 & 448.7 \\
\hline $2 \mathrm{wt} \% \mathrm{Ba}_{2} \mathrm{SiO}_{4}: \mathrm{Eu}[3]$ & -1.80 & -16.23 & 51.58 & 375.1 & - & 445.6 \\
\hline $5 \mathrm{wt} \% \mathrm{Ba}_{2} \mathrm{SiO}_{4}: \mathrm{Eu}$ & -1.42 & -16.78 & -50.56 & 372.8 & - & 448.1 \\
\hline $10 \mathrm{wt} \% \mathrm{Ba}_{2} \mathrm{SiO}_{4}: \mathrm{Eu}$ & -1.28 & -14.23 & -48.80 & 374.6 & - & 450.2 \\
\hline
\end{tabular}



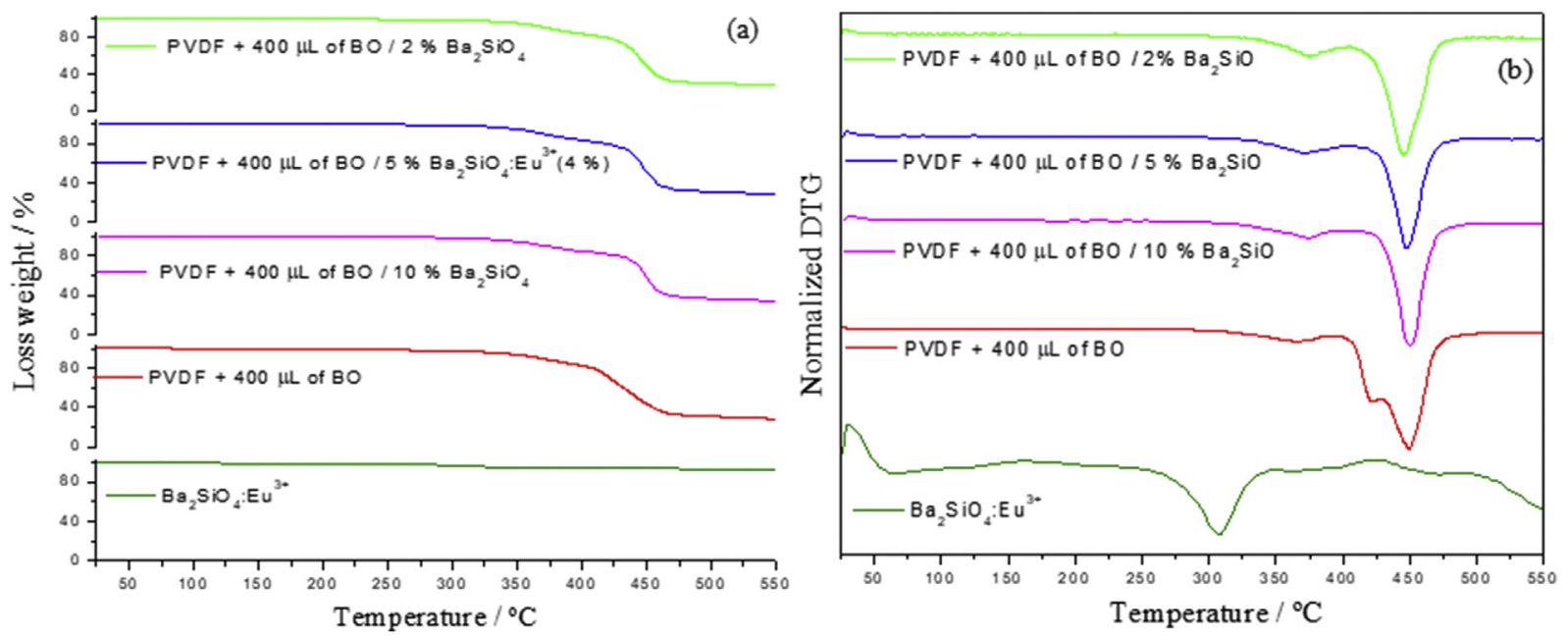

Fig. 4. TG thermograms (a) and DTG (b) of the synthesized PVDF membranes with the same amount of $\mathrm{BO}$ and varying the amount of $\mathrm{Ba}_{2} \mathrm{SiO}_{4}$ :Eu ${ }^{3+}$.

Table 2

Glass transition temperature $\left(\mathrm{T}_{\mathrm{g}}\right)$, melting temperature $\left(\mathrm{T}_{\mathrm{m}}\right)$, beginning melting temperature $\left(\mathrm{T}_{\text {onset }}\right)$, heat of fusion $\left(\Delta \mathrm{H}_{\mathrm{m}}\right)$, entropy variation in the melting process $\left(\Delta \mathrm{S}_{\mathrm{m}}\right)$ and crystallinity degree $(\chi)$.

\begin{tabular}{|c|c|c|c|c|c|c|}
\hline Membrane & $\mathrm{T}_{\mathrm{g}} /{ }^{\circ} \mathrm{C}$ & $\mathrm{T}_{\mathrm{m}} /{ }^{\circ} \mathrm{C}$ & $\mathrm{T}_{\text {onset }} /{ }^{\circ} \mathrm{C}$ & $\Delta \mathrm{H}_{\mathrm{m}} / \mathrm{J} \mathrm{g}^{-1}$ & $\Delta \mathrm{S}_{\mathrm{m}} / \mathrm{J} \mathrm{g}^{-1} \mathrm{~K}^{-1}$ & $\chi(\%)$ \\
\hline Pure PVDF & -35.9 & 171.6 & 161.1 & 32.3 & 0.07 & 35.7 \\
\hline $\mathrm{PVDF}+100 \mu \mathrm{L}$ BO & -50.3 & 170.7 & 161.9 & 28.5 & 0.06 & 31.5 \\
\hline $\mathrm{PVDF}+200 \mu \mathrm{L}$ BO & -56.0 & 170.5 & 161.5 & 28.5 & 0.06 & 31.5 \\
\hline $\mathrm{PVDF}+300 \mu \mathrm{L}$ BO & -45.5 & 171.4 & 161.2 & 26.7 & 0.06 & 29.5 \\
\hline $\mathrm{PVDF}+400 \mu \mathrm{L} \mathrm{BO}$ & -58.2 & 171.0 & 162.5 & 26.1 & 0.06 & 28.9 \\
\hline $\mathrm{PVDF}+500 \mu \mathrm{L} \mathrm{BO}$ & -41.2 & 170.1 & 161.9 & 28.1 & 0.06 & 31.1 \\
\hline $2 \% \mathrm{Ba}_{2} \mathrm{SiO}_{4}: \mathrm{Eu}[3]$ & -59.4 & 171.9 & 161.6 & 25.2 & 0.05 & 28.4 \\
\hline $5 \% \mathrm{Ba}_{2} \mathrm{SiO}_{4}: \mathrm{Eu}[3]$ & -42.4 & 171.9 & 163.8 & 24.9 & 0.05 & 29.0 \\
\hline $10 \% \mathrm{Ba}_{2} \mathrm{SiO}_{4}: \mathrm{Eu}$ [3] & -59.1 & 171.3 & 163.3 & 23.1 & 0.05 & 28.4 \\
\hline
\end{tabular}

evidenced by XRD data analysis. From the PVDF melting point, it is possible to estimate the polymer crystallinity degree $(\chi)$ by the following equation (1) [49].

$\chi=\frac{\Delta H_{m}}{W \cdot \Delta H_{m}^{o}} \times 100(\%)$

Where $\Delta \mathrm{H}_{\mathrm{m}}$ is the experimental heat of fusion, $\mathrm{W}$ is the PVDF content in the PVDF membranes and $\Delta \mathrm{H}_{\mathrm{m}}{ }^{\circ}$ is the heat of fusion for PVDF with crystallinity of $100 \%$. A value of $90.4 \mathrm{~J} \mathrm{~g}^{-1}$ has been used for $\mathrm{AH}_{\mathrm{m}}$ [50]. Also, as the melting temperature is constant in the melting process, it is possible to estimate the entropy variation $\left(\Delta S_{m}\right)$ for the melting process by equation (2).

$T_{m}=\frac{\Delta H_{m}}{\Delta S_{m}}$

The PVDF crystallinity decreases with the addition of BO up to $400 \mu \mathrm{L}$, then, the crystallinity increases again for the membrane with $500 \mu \mathrm{L}$ of BO. This behavior is in agreement with that verified for the membranes thicknesses, i.e., when the crystallinity decreases, the thickness increases.

A glass transition $\left(\mathrm{T}_{\mathrm{g}}\right)$ was observed in the polymers DSC scans, Fig. S6(b) which values are also listed in Table 2. The glass transition for pure PVDF membrane occurs at $-35.5^{\circ} \mathrm{C}$ which is in agreement with the literature [51]. For PVDF membranes containing BO, the glass transition values decrease when compared to the pure PVDF membrane. Many authors have been assigned the $T_{g}$ decrease to the addictive plasticizer effect due to the increase of the free volume in the polymeric host $[31,52,53]$. In this way, the decrease of $T_{g}$ for the synthesized membranes confirms the BO plasticizer effect that makes the final material softer and more flexible than the pure PVDF membrane. Such effect was reported by others authors for different membranes $[54,55]$. However, the trend of decreasing the $\mathrm{T}_{\mathrm{g}}$ occurs up to the membrane contains $400 \mu \mathrm{L}$ of $\mathrm{BO}$, then, the $\mathrm{T}_{\mathrm{g}}$ increases again. As consequence, the free volume in the polymeric matrix increases until we added $400 \mu \mathrm{L}$ of BO, justifying the thickness behavior observed for the membranes.

The result of DSC scans for the composite membranes with $\mathrm{Ba}_{2} \mathrm{SiO}_{4}: \mathrm{Eu}^{3+}$ are shown in Fig. 5 (a) and some important results are summarized in Table 2. The inclusion of $\mathrm{Ba}_{2} \mathrm{SiO}_{4}: \mathrm{Eu}^{3+}$ does not lead to major changes in the PVDF scan profile; however, a new thermal event was detected at $330{ }^{\circ} \mathrm{C}$ corresponding to $\mathrm{BaCO}_{3}$ decomposition, in agreement with the previous results discussed in TG measurements. On the other hand, the PVDF crystallinity as well as the $T_{g}$ values, shown in Table 2, slightly varies with the phosphor addition in the membrane composition, except for the membrane containing $5 \mathrm{wt} \%$ of phosphor. Furthermore, the $\mathrm{Ba}_{2} \mathrm{SiO}_{4}: \mathrm{Eu}^{3+}$ addition in PVDF membranes decreases the PVDF crystallinity, as it has indicated by XRD before.

The excitation and emission spectra at room temperature for PVDF membranes obtained with different amount of BO are shown in Fig. S7. The excitation spectra, Fig. S7(a), for pure PVDF and PVDF/BO membranes exhibit two broad bands centered at 316 and $368 \mathrm{~nm}$, in the ultraviolet range. Although no reports in the literature were found for the PVDF intrinsic luminescence, it is possible to infer that the PVDF absorption in the UV or visible region arises from electronic transitions from the ground state to higher energy levels related to the $\sigma$ and $n$ orbitals of C-F single bond. A. K. Srivastava et al. (2000) report the UVVis absorption spectra of PVDF, wherein it is shown that PVDF has five characteristic bands at $315 \mathrm{~nm}, 325 \mathrm{~nm}, 360 \mathrm{~nm}, 425 \mathrm{~nm}$ and $600 \mathrm{~nm}$ which were correlated with the electronic transition occurring in C-F 

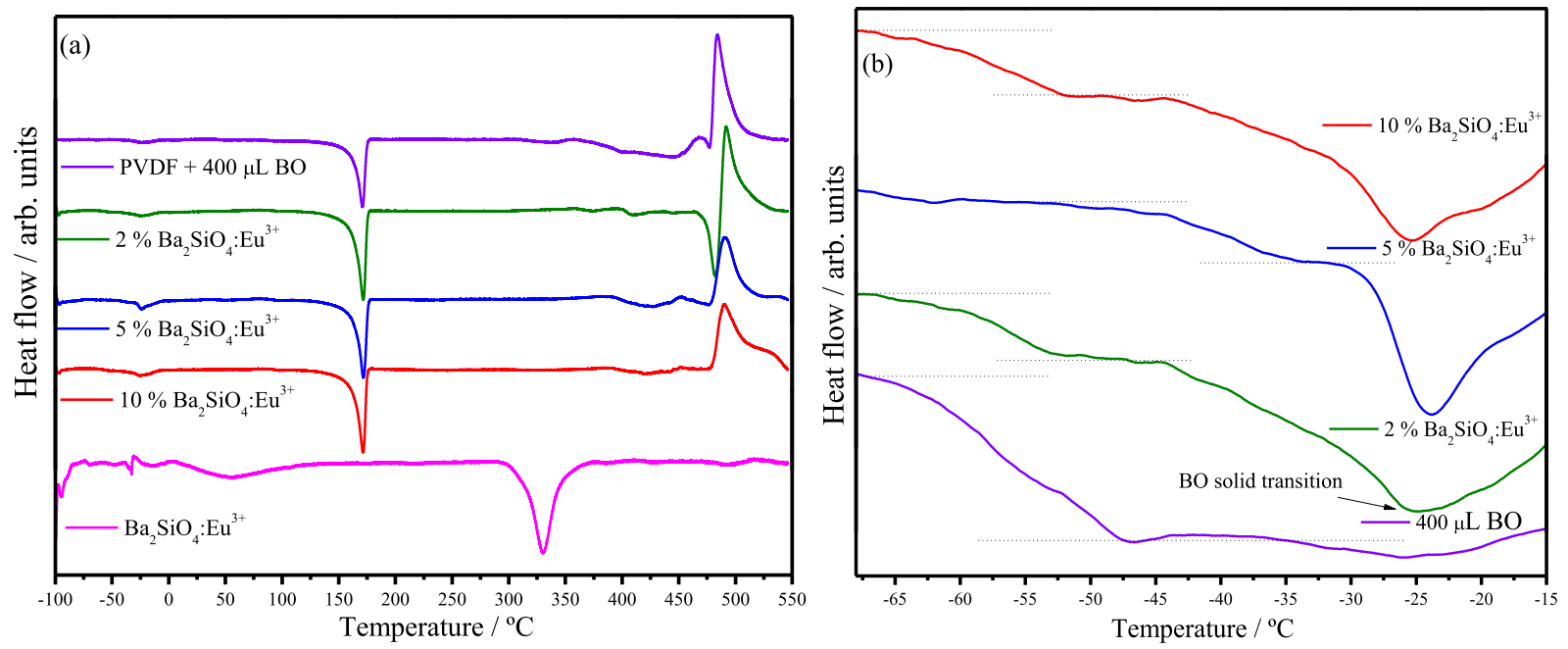

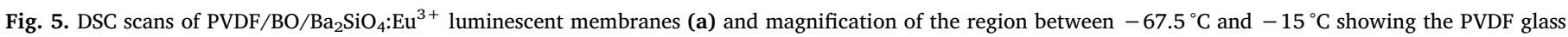
transition (b).

bounds [56]. Molecules containing electrons that are not directly involved in bonding, e.g., the compounds containing fluorine, chlorine, nitrogen, and oxygen, are capable of to produce these types of characteristic absorptions due to the transition of non-bonding electrons. From the emission spectra, Fig. S7 (b), it was observed an increase in the emission intensity of the PVDF membrane with the BO amount up to $400 \mu \mathrm{L}$ and then decreased when we added $500 \mu \mathrm{L}$, presenting an extra band at $350 \mathrm{~nm}$. However, this intensity is very low and was only used to understand the $\mathrm{BO}$ influence on the PVDF properties. As the thickness of the membranes increases with BO amount, the light scattering inside the membrane is intensified since the free volume decreases, as shown by DSC, as consequence, more PVDF chains can be excited by the light and the emission intensity increases, this intensification is also related to the larger optical paths directly linked to the thickness. The effects of the BO in the PVDF properties are compared in Fig. S8.

The excitation and emission spectra at room temperature of all $\mathrm{Ba}_{2} \mathrm{SiO}_{4}$ :Eu-doped PVDF membranes with $400 \mu \mathrm{L}$ of $\mathrm{BO}$ are shown in Fig. 6. A broad $\mathrm{Eu}^{3+}-\mathrm{O}^{2-}$ charge transfer band (CT) is observed below $275 \mathrm{~nm}$ in the $\mathrm{Ba}_{2} \mathrm{SiO}_{4}: \mathrm{Eu}^{3+}$ excitation spectra as well as the expected narrow lines with lower relative intensity related to the $f-f \mathrm{Eu}^{3+}$ transitions, which are forbidden by Laporte parity selection rule. For the membrane doped with $10 \mathrm{wt} \%$, the excitation transitions related to the phosphor can be detected, Fig. 6(a), but no excitation was observed for the samples doped with $2 \mathrm{wt} \%$ and $5 \mathrm{wt} \%$. The emission spectra under $250 \mathrm{~nm}$ excitation for pure $\mathrm{Ba}_{2} \mathrm{SiO}_{4}: \mathrm{Eu}^{3+}(4 \%)$, Fig. 6(b) is dominated by narrow bands related to the ${ }^{5} \mathrm{D}_{0} \rightarrow{ }^{7} \mathrm{~F}_{\mathrm{J}}(\mathrm{J}=1,2$ and 4) transitions, mainly in the red region. The most intense band is attributed to the ${ }^{5} \mathrm{D}_{0} \rightarrow{ }^{7} \mathrm{~F}_{2}$ transition meaning that the $\mathrm{Eu}^{3+}$ ions are occupying a lowsymmetry site in $\mathrm{Ba}_{2} \mathrm{SiO}_{4}$ crystalline structure even when this material is dispersed in the polymeric host [57]. The color coordinates $\mathrm{x}=0.684$, and $\mathrm{y}=0.314$ were determined for the $10 \mathrm{wt} \%$-doped membrane, with $100 \%$ of color purity at $250 \mathrm{~nm}$ excitation (see the International Commission on Illumination chromaticity diagrams in Fig. S9), which guarantee a pure red color for the membrane.

For the phosphor-doped membranes, only the $10 \mathrm{wt} \%$ sample exhibits the characteristic emission lines of $\mathrm{Eu}^{3+}$ showing that in membranes with $5 \mathrm{wt} \%$ and $2 \mathrm{wt} \%$ of $\mathrm{Ba}_{2} \mathrm{SiO}_{4}: \mathrm{Eu}^{3+}$, the concentration of the phosphor particles are too low to be detected. Another explanation comes from the chemical mapping measurements which demonstrated that the phosphor particles are probably located in an inner part of the membrane, and for this reason the membrane may act as a filter for UV light, preventing the phosphor to be excited. The emission spectra displayed in Fig. 6(b), reveal that emission profiles of the $\mathrm{Ba}_{2} \mathrm{SiO}_{4}: \mathrm{Eu}^{3+}$ phosphor before and after incorporation into the composite membrane at $10 \mathrm{wt} \%$ are similar and not affected by the polymer matrix.

The experimental lifetime value for the $\mathrm{Eu}^{3+}{ }^{5} \mathrm{D}_{0}$ excited level was

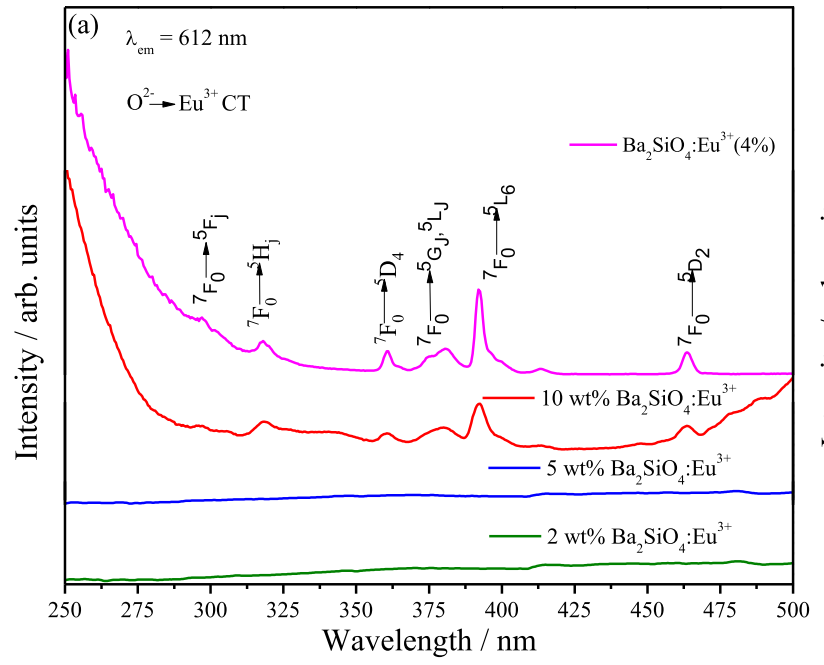

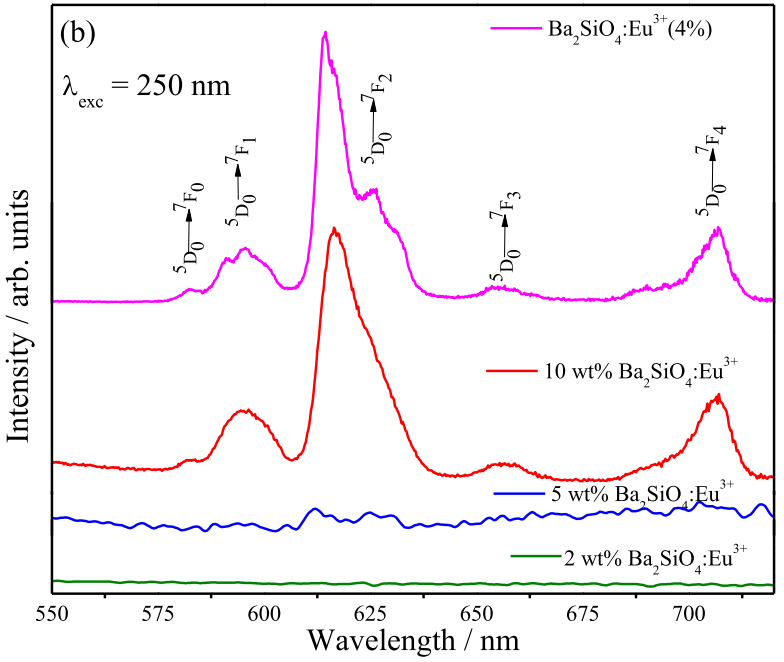

Fig. 6. Excitation (a) and emission (b) spectra of $\mathrm{Ba}_{2} \mathrm{SiO}_{4}: \mathrm{Eu}^{3+}$-doped PVDF membranes measured at room temperature. 
Table 3

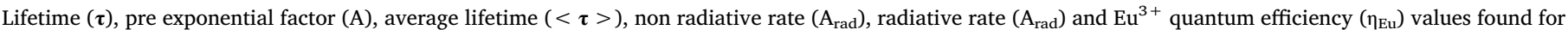
the $10 \mathrm{wt} \%$-doped membrane compared to the bulk $\mathrm{Ba}_{2} \mathrm{SiO}_{4}: \mathrm{Eu}^{3+}(4 \%)$ particles.

\begin{tabular}{|c|c|c|c|c|c|c|c|c|}
\hline Sample & $\begin{array}{l}\tau_{1} \\
(\mathrm{~ms})\end{array}$ & $\mathrm{A}_{1}$ & $\begin{array}{l}\tau_{2} \\
(\mathrm{~ms})\end{array}$ & $\mathrm{A}_{2}$ & $<\tau>(\mathrm{ms})$ & $A_{\text {nrad }}\left(s^{-1}\right)$ & $\begin{array}{l}A_{\text {rad }} \\
\left(s^{-1}\right)\end{array}$ & $\eta_{\mathrm{Eu}}(\%)$ \\
\hline $10 \mathrm{wt} \%$-doped membrane & 0.21 & 1141 & 1.86 & 470 & 1.50 & 187 & 480 & 72 \\
\hline $\mathrm{Ba}_{2} \mathrm{SiO}_{4}: \mathrm{Eu}^{3+}(4 \%)[15]$ & 0.14 & $2.5 \times 10^{5}$ & 1.59 & $1.5 \times 10^{5}$ & 1.34 & 237 & 509 & 68 \\
\hline
\end{tabular}

evaluated through an emission decay curve shown in Fig. S10. The decay curve was best fitted by a biexponential adjustment. The estimated lifetime values are shown in Table 3 , and the average lifetime was calculated using equation (3), where the term $A_{i}$ is the pre-exponential factor associate to each lifetime $\left(\tau_{\mathrm{i}}\right)$ values [58]. The average lifetime value of $1.5 \mathrm{~ms}$ is higher than that for the $\mathrm{Ba}_{2} \mathrm{SiO}_{4}: \mathrm{Eu}^{3+}$ bulk $(1.34 \mathrm{~ms})$, as represented in Table 3 , indicating that the non-radiative losses from the ${ }^{5} \mathrm{D}_{0}$ level have decreased. This probably occurs because the phosphor particles are protected against luminescent deactivators such as $\mathrm{CO}_{2}$ and $\mathrm{H}_{2} \mathrm{O}$.

$\tau=\frac{\sum A_{i} \tau_{i}^{2}}{\sum A_{i} \tau_{i}}$

From the lifetime value, it is possible to calculate the $\mathrm{Eu}^{3+}$ quantum efficiency ( $\eta_{\mathrm{Eu}}$, Equation (4)), that is the greatness that correlates the radiative $\left(A_{\text {rad }}\right)$ and the non-radiative $\left(A_{\text {nrad }}\right)$ contributions from an emitting level. The $A_{\text {rad }}$ is determined from equations (5) and (6).

$\eta=\frac{A_{\text {rad }}}{A_{\text {rad }}+A_{\text {nrad }}}$

$A_{0-\lambda}=A_{0-j}=A_{01} \frac{I_{0-j}}{I_{0-1}} \frac{h v_{0-1}}{h v_{0-j}}$

$A_{\text {rad }}=\sum_{J} A_{0-j}$

Where $A_{01}$ is equals to $14.65 . \mathrm{n}^{3}$ ( $n$ is the refractive index considered in this case as 1.7$)^{15}$ and corresponds to the Einstein's coefficient for spontaneous emission; [59] and $I_{0-\mathrm{j}}$ is the integrated area under the respective ${ }^{5} \mathrm{D}_{0} \rightarrow{ }^{7} \mathrm{~F}_{j}$ transitions. The $A_{\text {nrad }}$ is determined from the lifetime value by using equation (7).

$A_{\text {total }}=\frac{1}{\tau}=A_{\text {rad }}+A_{\text {nrad }}$

The calculated $\eta_{\mathrm{Eu}}$ for the $10 \mathrm{wt} \%$ doped membrane is shown in Table 3 , and it has been compared to the bulk $\mathrm{Ba}_{2} \mathrm{SiO}_{4}: \mathrm{Eu}^{3+}$ data published by Bispo et al. [15] As expected, the non-radiative contribution is lower in the particles immobilized in the PVDF membrane, when compared with the bulk form, resulting in a higher $\eta_{\mathrm{Eu}}$ for the membrane compared to the bulk phosphor, demonstrating that the particles incorporation in the PVDF membranes is a suitable way to improve the $\mathrm{Eu}^{3+}$ emission in the $\mathrm{Ba}_{2} \mathrm{SiO}_{4}: \mathrm{Eu}^{3+}$ system.

\section{Conclusions}

The synthesis and characterization (structural, thermal, morphological and optical) of a composite based on $\mathrm{Ba}_{2} \mathrm{SiO}_{4}: \mathrm{Eu}^{3+}$-doped PVDF polymeric membrane was presented. Buriti oil was applied as plasticizer for PVDF and its use increase the thickness and the thermal stability of the membranes up to $400 \mu \mathrm{L}$. The introduction of the $\mathrm{Ba}_{2} \mathrm{SiO}_{4}: \mathrm{Eu}^{3+}$ particles into the PVDF matrix causes small changes in the organization. However, the particles slightly increase the PVDF thermal stability. The doped membrane with $10 \mathrm{wt} \%$ of the phosphor exhibited good red emission arising from the $\mathrm{Ba}_{2} \mathrm{SiO}_{4}$ :Eu. The particle incorporation also increases the $\mathrm{Eu}^{3+}$ quantum efficiency to $72 \%$. Therefore, the luminescent composite material developed in this study could be successfully applied in optical devices as light-emitting diodes.

\section{Conflicts of interest}

There are no conflicts to declare.

\section{Acknowledgements}

The authors are thankful to the Brazilian agency CNPq (307385/ 20159) for the financial research support. Airton G. B. Junior and Ana M. Pires are particularly grateful to the São Paulo research Foundation (FAPESP) for the award of some scholarships (Grant No. 2012/13876-9, 2015/10394-1, and 2016/20421-9). Laboratório de microscopia eletrônica de varredura (FCT/UNESP), Laboratório Multiusuário de Análises Químicas (IQ/UNESP - Araraquara), and Laboratório de difração de raios X (FCT/UNESP).

\section{Appendix A. Supplementary data}

Supplementary data related to this article can be found at http://dx. doi.org/10.1016/j.matchemphys.2018.06.057.

\section{References}

[1] H.J. Bolink, H. Brine, E. Coronado, M. Sessolo, Adv. Mater. 22 (2010) 2198-2201.

[2] B. Chen, J. Feng, J. Phys. Chem. C 119 (2015) 7865.

[3] S. Lee, J. Park, Sensor. Actuator. B Chem. 249 (2017) 364.

[4] M.H. Gu, J. Zhang, X.L. Wang, W.Z. Ma, J. Appl. Polym. Sci. 102 (2006) 3714.

[5] M.G.A. Vieira, M.A. Silva, L.O. Santos, M.M. Beppu, Eur. Polym. J. 47 (2011) 254.

[6] I.V. Taydakov, S.A. Ambrozevich, E.A. Varaksina, A.G. Vitukhnovsky, A.A. Tyutyunov, O.A. Melnik, J. Russ. Laser Res. 37 (2016) 192.

[7] J. Garcia-Torres, P. Bosch-Jimenez, E. Torralba-Calleja, M. Kennedy, H. Ahmed, J. Doran, D. Gutierrez-Tauste, L. Bautistaa, M. DellaPirriera, J. Photochem. Photobiol.A 283 (2014) 8.

[8] G. Vicentini, L.B. Zinner, J. Zukerman-Schpector, K. Zinner, Coord. Chem. Rev. 196 (2000) 353.

[9] H. Pan, X. Li, J. Zhang, L. Guan, H. Su, F. Teng, Mater. Lett. 155 (2015) 106.

[10] G. Gasparotto, M.A. Cebim, M.S. Goes, S.A.M. Lima, M.R. Davolos, J.A. Varela, C.O. Paiva-Santos, M.A. Zaghete, J. Appl. Phys. 106 (2009) 063509.

[11] X. Shang-Da, M.F. Reid, J. Phys. Chem. Solid. 54 (1993) 777.

[12] A.M. Pires, M.R. Davolos, Chem. Mater. 13 (2001) 21-27.

[13] A.M. Pires, M.R. Davolos, O.M.L. Malta, J. Lumin. 72 (1997) 244.

[14] P.A. Raymundo-Pereira, D.A. Ceccato, D.A.G.B. Junior, M.F.S. Teixeira, S.A.M. Lima, A.M. Pires, RSC Adv. 6 (2016) 104529.

[15] A.G. Bispo Jr., D.A. Ceccato, S.A.M. Lima, A.M. Pires, RSC Adv. 7 (2017) 53752

[16] A.G. Bispo Jr., S.A.M. Lima, A.M. Pires, J. Lumin. 199 (2018) 372.

[17] A.L. Gomes, R. Lang, E. Armelin, C. Alemán, J.S.C. Campos, J. Mater. Chem. C 2 (2014) 2502.

[18] J. Jia, D. Li, H. Jia, A. Zhang, P. Tao, X. Liu, Opt. Mater. 72 (2017) 602.

[19] Q.X. Chen, P.A. Payne, Technology 6 (1995) 249.

[20] N. Jia, Q. He, J. Sun, G. Xia, R. Song, Polym. Test. 57 (2017) 302.

[21] N. Furusho, T. Komatsu, T. Nakagawa, A study of thermal degradation of several halogen-containing polymers by torsional braid analysis, Bull. Chem. Soc. Jpn. 47 (1974) 1573.

[22] B.K. Paul, D. Roy, S. Batabyal, A. Bhattacharya, P. Nandy, S. Das, Mater. Chem. Phys. 187 (2017) 119.

[23] F. He, K. Lin, D. Shi, H. Wu, H. Huang, J. Chen, F. Chen, K. Lam, Compos. Sci. Technol. 137 (2016) 138.

[24] A.J. Lovinger, Science 220 (1983) 1115.

[25] Y.L. Liu, Y. Li, J.T. Xu, Z.Q. Fan, ACS Appl. Mater. Interfaces 2 (2010) 1759.

[26] R. Hasegawa, Y. Takahash, H. Tadokoro, Y. Chatani, Polym. J. 3 (1972) 600.

[27] S.J. Kang, Y.J. Park, J. Sung, P.S. Jo, C. Park, K.J. Kim, B.O. Cho, Appl. Phys. Lett. $92(2008) 3$.

[28] M.H. Gu, J. Zhang, X.L. Wang, H.J. Taoa, L.T. Ge, Desalination 192 (2006) 160.

[29] C. Du, Y. Xu, B. Zhu, J. Appl. Polym. Sci. 114 (2009) 3645.

[30] M.L.S. Albuquerque, I. Guedes, P. Alcantara, S.G.C. Moreira, N.M.B. Neto, D.S. Correa, S.C. Zílio, J. Braz. Chem. Soc. 16 (2005) 1113.

[31] J.A. Duraes, A.L. Drummond, T.A.P.F. Pimentel, M.M. Murta, S.G.C. Moreira, M.;J.A. Sales, J. Therm. Anal. Calorim. 92 (2008) 529. 
[32] D. Schlemmer, E. R. Oliveira, and M. J. A. Sales, Jc 2007, 87, 635.

[33] A. J. Lovinger, D.C. Basset, 1982, pp. 195-273.

[34] X. Wang, L. Zhang, D. Sun, Q. An, H. Chen, Desalination 236 (2009) 170.

[35] J. Hirschinger, D. Schaefer, H.W. Spiess, A.J. Lovinger, Macromolecules 24 (1991) 2428.

[36] J. Song, C. Lu, D. Xu, Y. Ni, Y. Liu, Z. Xu, J. Liu, Polym. Int. 59 (2010) 954.

[37] F. Shi, J. Ma, P. Wang, Y. Ma, J. Taiwan Inst. Chem. Eng. 43 (2012) 980.

[38] B. Crist, J.M. Schultz, Prog. Polym. Sci. 56 (2016) 1.

[39] J.A. Duraes, A.L. Drummond, T.A.P.F. Pimentel, M.M. Murta, F.S. Bicalho, S.G.C. Moreira, M.J.A. Sales, Eur. Polym. J. 42 (2006) 3324.

[40] K.M.S. Meera, R.M. Sankar, A. Murali, S.N. Jaisankar, A.B. Mandal, Colloids Surf., B 90 (2012) 204.

[41] S. Zulfiqar, M. Zulfiqar, M. Rizvi, A. Munir, I.C. McNeill, Polym. Degrad. Stabil. 43 (1994) 423.

[42] L.F. Malmonge, L.H.C. Mattoso, Polymer 41 (2000) 8387.

[43] N.H. Jayadas, K.P. Nair, Tribol. Int. 39 (2006) 873.

[44] F.S. Al-Hazmi, D.M. Leeuw, A.A. Al-Ghamdi, F.S. Shokr, Curr. Appl. Phys. 17 (2017) 1181.

[45] W.E. Mahmoud, A.M.Y. El-Lawindy, M.H. El Eraki, H.H. Hassan, Sens. Actuators A
Phys. 136 (2007) 229.

[46] F.O. Cedeo, M.M. Prieto, A. Espina, J.R. Garcia, Thermochim. Acta 369 (2001) 39.

[47] A. Garcia-Quiroz, S.G.C. Moreira, A.V. de Morais, A.S. Silva, G.N. Rocha, P. Alcântara, Instrum. Sci. Technol. 31 (2003) 93.

[48] V. Sencadas, S. Lanceros-Méndez, J.F. Mano, Thermochim. Acta 424 (2004) 201.

[49] Z. Liu, P. Marechal, R. Jerome, Polymer 38 (1997) 4925.

[50] J.S.C. Campos, A.A. Ribeiro, C.X. Cardoso, Mater. Sci. Eng. B 136 (2007) 123.

[51] J. Inderherbergh, Ferroelectrics 115 (1991) 295-302.

[52] K. Kawai, Y. Hagura, Carbohydr. Polym. 89 (2012) 836.

[53] S.L. Shamblin, E.Y. Huang, G. Zografi, J. Therm. Anal. Calorim. 47 (1996) 1567.

[54] B.C. Hancock, C.R. Dalton, M.J. Pikal, S.L. Shamblin, Pharm. Res. 15 (1998) 762.

[55] G. Sartor, E. Mayer, G.P. Johari, Biophys. J. 66 (1994) 249-258.

[56] A.K. Srivastava, H.S. Virk, Bull. Mater. Sci. 23 (2000) 533.

[57] T. Grzyb, M. Wecławiak, J. Rozowska, S. Lis, J. Alloy. Comp. 576 (2013) 345.

[58] Y. Ma, H. Wang, W. Liu, Q. Wan, J.E. Xu, Y. Tang, J. Chem. Phys. B 113 (2009) 14139.

[59] A.P. Duarte, M. Gressier, M. Menu, J. Dexpert-Ghys, J.M.A. Caiut, S.J.L. Ribeiro, J. Chem. Phys. C 116 (2012) 505-515. 